Article

\title{
Thermal Analysis of a Disposable, Instrument-Free DNA Amplification Lab-on-a-Chip Platform
}

\author{
Tamás Pardy ${ }^{1,2, *(\mathbb{D})}$, Toomas Rang ${ }^{1}$ and Indrek Tulp ${ }^{2,3}$ (1) \\ 1 Thomas Johann Seebeck Department of Electronics, Tallinn University of Technology, 12616 Tallinn, Estonia; \\ toomas.rang@ttu.ee \\ 2 Selfdiagnostics Deutschland GmbH, 04103 Leipzig, Germany; indrek.tulp@selfdiagnostics.com \\ 3 Institute of Technology, University of Tartu, 50411 Tartu, Estonia \\ * Correspondence: tamas.pardy@ttu.ee; Tel.: +372-5823-0626
}

Received: 26 April 2018; Accepted: 1 June 2018; Published: 4 June 2018

\begin{abstract}
Novel second-generation rapid diagnostics based on nucleic acid amplification tests (NAAT) offer performance metrics on par with clinical laboratories in detecting infectious diseases at the point of care. The diagnostic assay is typically performed within a Lab-on-a-Chip (LoC) component with integrated temperature regulation. However, constraints on device dimensions, cost and power supply inherent with the device format apply to temperature regulation as well. Thermal analysis on simplified thermal models for the device can help overcome these barriers by speeding up thermal optimization. In this work, we perform experimental thermal analysis on the simplified thermal model for our instrument-free, single-use LoC NAAT platform. The system is evaluated further by finite element modelling. Steady-state as well as transient thermal analysis are performed to evaluate the performance of a self-regulating polymer resin heating element in the proposed device geometry. Reaction volumes in the target temperature range of the amplification reaction are estimated in the simulated model to assess compliance with assay requirements. Using the proposed methodology, we demonstrated our NAAT device concept capable of performing loop-mediated isothermal amplification in the $20-25^{\circ} \mathrm{C}$ ambient temperature range with $32 \mathrm{~min}$ total assay time.
\end{abstract}

Keywords: Lab-on-a-Chip (LoC); finite element modelling; resistive heating; Point-of-Care (PoC); temperature control; computer aided design; microfluidics; isothermal nucleic acid amplification tests; NINAAT; NAAT

\section{Introduction}

Despite a significant drop in mortality rates associated with infectious diseases since 1990, they still constituted over $80 \%$ of all health hazards in the last decade worldwide [1]. Pathogens such as sexually transmitted diseases often have a late onset of symptoms and can have severe complications, such as infertility [2]. To prevent or effectively contain outbreaks, it is essential to have Point-of-Care (PoC) diagnostics that comply with the ASSURED (affordable, sensitive, specific, user-friendly, rapid, equipment-free and delivered) guidelines of the World Health Organization (WHO) [3]. Novel PoC tests are compliant with these guidelines and are capable of executing nucleic acid amplification tests (NAAT) in a Lab-on-a-Chip (LoC) format. These devices offer comparable performance to tests at clinical laboratories but in a far smaller and more portable package [4-6]. LoC NAAT tests can help decentralize testing for infectious diseases, enabling a prompt diagnosis at small clinics or even at home, as well as faster treatment of infections and better containment of pathogens. All NAAT protocols require temperature regulation to sustain the amplification reaction, but unlike the gold-standard PCR (polymerase chain reaction) protocol, isothermal NAAT protocols do not require thermal cycling, only a single reaction temperature (typically in the $20-70{ }^{\circ} \mathrm{C}$ range) maintained for 
the assay duration [7-9], which makes them favorable for portable implementations. However, their realization in a compact PoC device, especially a disposable one, is still very challenging due to space, power and cost constraints on the heating element and power supply [5]. These factors limit commercialization efforts and thereby availability to the public.

A compact, self-contained, instrument-free LoC NAAT device that meets the ASSURED criteria must have no external component and must be as small and compact as possible. However, existing demonstrations in the literature were primarily instrumented devices and relied on external means for temperature control, most commonly thermostat-regulated Peltier elements, such as those in PCR thermal cyclers [10-13]. The use of third-party external thermoregulation places end-user device price in the 1000-10,000 EUR range. The Alere I-Influenza A\&B [14] system is a prime example of currently available commercial LoC NAAT devices: It consists of a stationary unit, which includes the heating system (powered from the supply grid) as well as disposable single-use microfluidic cartridges that handle the sample and execute the NAAT protocol. These benchtop instruments are not portable or instrument free, as well as costing about 10,000 EUR. Certain integrated temperature control solutions in the literature employed electrical heating elements attached to the LoC component or built into the chip itself, using thin film heaters or micro-Peltier cells [15-21]. However, both of these options required an external thermostat, resulting in a minimally-instrumented device rather than a completely equipment free one. Having to use microfabrication along with the required supporting electronics, the end-user price for these systems could range from 500-5000 EUR, plus 100-200 EUR for each replaceable fluidic cartridge. Self-regulating electrical heaters offer an attractive alternative in that they require no additional components for regulation [22-24] and rely on the PTCR (positive temperature coefficient of resistance) effect for control. Self-regulating heaters will limit their input current above a specific set temperature defined by material properties, in turn limiting their heat output. However, due to the open-loop nature of this control method, the thermal system must be carefully adjusted to expected operating parameters, as well as have a generally lower power efficiency than thermostat-regulated heaters [24]. Cost is an important design factor in instrument-free LoC NAAT devices. Exothermic chemical reactions [25-27] offer a very cost-effective approach to integrated heating. Oxidative reactions, such as the corrosion of magnesium-iron alloy release a significant amount of heat, in which heat release can be controlled by the addition of phase-change materials that melt in the target temperature range and dissipate excess heat. A single reaction could be done from 1-10 EUR. However, while cost effective and instrument free, the heat output of these reactions is also hard to regulate and chemical heaters tend to have a larger footprint than electrical counterparts with a similar heat output. The design complexity and higher development risk associated with chemical heaters make them less favorable for commercial devices. Common electrical heating options reported in the literature are categorized in Table 1, comparing chip dimensions, power consumption and estimated end-user price as well as whether a thermostat is required for thermal regulation. Furthermore, we assess whether the demonstrated solutions are self-contained, that is, every system component is housed within a single enclosure and the device is completely free of external instrumentation (including an external power supply). Comparing these parameters, it is apparent that self-regulating PTCR heating elements offer an ideal mix of dimensions, power consumption, production cost as well as portability for disposable LoC NAAT applications. Moreover, they enable complete device integration into a single package that is disposable as a unit. 
Table 1. Comparison of electrical heating solutions for LoC NAAT devices reported in the literature.

\begin{tabular}{ccccccc}
\hline Heating Solution & Self-Contained? & Thermostat? & $\begin{array}{c}\text { Chip } \\
\text { Dimensions } \\
{[\mathbf{c m}]}\end{array}$ & $\begin{array}{c}\text { Power } \\
\text { Consumption } \\
{[\mathbf{W}]}\end{array}$ & $\begin{array}{c}\text { End-User Device } \\
\text { Price (Estimate) [€] }\end{array}$ & Source \\
\hline External Peltier & No & Yes & $\sim 4 \times 4 \times 2$ & min. 80 & $\sim 1000-10,000$ & {$[10-13]$} \\
\hline Integrated resistive & $\begin{array}{c}\text { Examples } \\
\text { available }\end{array}$ & Yes & $\sim 8 \times 3 \times 1$ & $\sim 2-3$ & $\sim 500-5000$ & {$[15-19]$} \\
\hline Integrated $\mu$-Peltier & No & Yes & $\sim 2 \times 2 \times 0.3$ & $\sim 2-3$ & $\sim 500-5000$ & {$[20,21,28]$} \\
\hline $\begin{array}{c}\text { Integrated } \\
\text { self-regulating }\end{array}$ & Not reported & No & $\sim 5 \times 5 \times 0.3$ & $\sim 1.2-0.8$ & $\sim 500-1000$ & {$[24,29]$} \\
\hline $\begin{array}{c}\text { Integrated polymer } \\
\text { resin PTCR }\end{array}$ & Yes & No & $5.5 \times 9 \times 0.75$ & $1-0.6$ & $\sim 20-50$ & This work \\
\hline
\end{tabular}

In previous works, we demonstrated the methodology for simulated and experimental thermal analysis of LoC NAAT systems with integrated temperature control based on commercially available electrical heating elements [30-33]. We compared the performance of a commercially available self-regulating heating element to a thermostat-regulated etched foil heating element in LoC NAAT prototypes and concluded that self-regulating heating was the favorable option for disposable instrument-free LoC NAAT devices [33]. Furthermore, we demonstrated a self-regulating heater integrated with a LoC prototype system, with which we performed loop-mediated isothermal amplification (LAMP) in the $20-25{ }^{\circ} \mathrm{C}$ room temperature range [34]. In this work, we introduce the concept device of our instrument-free LoC NAAT platform and perform thermal analysis on it to verify that it is capable of supporting LAMP in the expected end-user environment. Experimental thermal characterization is performed on a 3D-printed thermal model. The model is then simulated via finite element modelling and both steady-state and transient thermal analysis are performed. Steady-state thermal analysis is used to determine reaction temperatures at specific ambient temperatures. Transient thermal analysis is performed at the most appropriate ambient temperature to simulate reaction temperatures over time. In both cases, reaction volumes in range will be estimated based on temperature distributions and used to assess expected LAMP performance and compliance with assay requirements.

\section{Materials and Methods}

\subsection{Heating Element and Thermal Interface}

Self-regulating resistive heating elements are electrical heaters capable of maintaining their set temperature without external regulation. PTCR (positive temperature coefficient of resistance) materials exhibit a rapid rise in resistance above a pre-determined threshold temperature and thereby limit their own input current. This allows precise temperature control within a well-defined ambient temperature range. In this paper, loop-mediated isothermal amplification (LAMP) is the protocol of choice, which provides the maximum yield within $60-65{ }^{\circ} \mathrm{C}$ temperature [7]. In our LAMP assay (detailed in our previous works [35-37]), we use Bsm polymerase, whose activity is higher than $80 \%$ within the $57-62{ }^{\circ} \mathrm{C}$ reaction temperature range, as demonstrated by Oscorbin et al. [38]. Therefore, we define this temperature range as the target for our heating system. Total assay time is defined as $30 \mathrm{~min}$, and $10 \mathrm{~min}$ is allowed for the heater to bring the reaction volume up to range (the assay requires at least $20 \mathrm{~min}$ in the correct range to finish with certainty). BM128 batch PTCR polymer heaters (Heatron Inc., Leavenworth, KS, USA) were designed with these parameters in mind (further information on BM series heaters is available in our previous work [34]). The heaters were designed for a $3 \mathrm{~V}_{\mathrm{DC}}$ driving voltage supplied by $2 x \mathrm{AAA}$ alkaline batteries. The nominal set temperature of the heaters was $66^{\circ} \mathrm{C}\left( \pm 2{ }^{\circ} \mathrm{C}\right)$ to ensure fast convergence to target.

The heater was built into a sub-assembly, which consisted of several layers (Figure 1c,d): The base layer was a $1.3 \mathrm{~mm}$ thick block of polyurethane foam (P/N 798-9310, RS Components, Corby, UK) with an adhesive layer facing the lower contact. The heater was attached with conductive PSA 
(pressure-sensitive adhesive) between the lower and upper contact. Both contacts were milled from 0.35 mm thick high-conductivity copper (P/N 680-959, RS Components, Corby, UK) sheets. Between the top contact and the reaction chambers was a block of acrylic foam (P/N 686-1107, RS Components, Corby, UK), self-adhesive on both sides, which conducted just the right amount of heat to the reaction liquid. The thermal interface between the heater and the heated liquid consisted of 4 layers with various thermal properties (summarized in Table 2). Therefore, parameters of this layer structure had to be optimized carefully to match operating conditions. The reaction liquid and the heater sub-assembly were separated by a $0.15 \mathrm{~mm}$ thick foil layer laminated onto the chip (Greiner MTP Sealers, Greiner Holding AG, Kremsmunster, Austria). No additional thermal interface material was used as the assembly was adhered to the microfluidic chip.

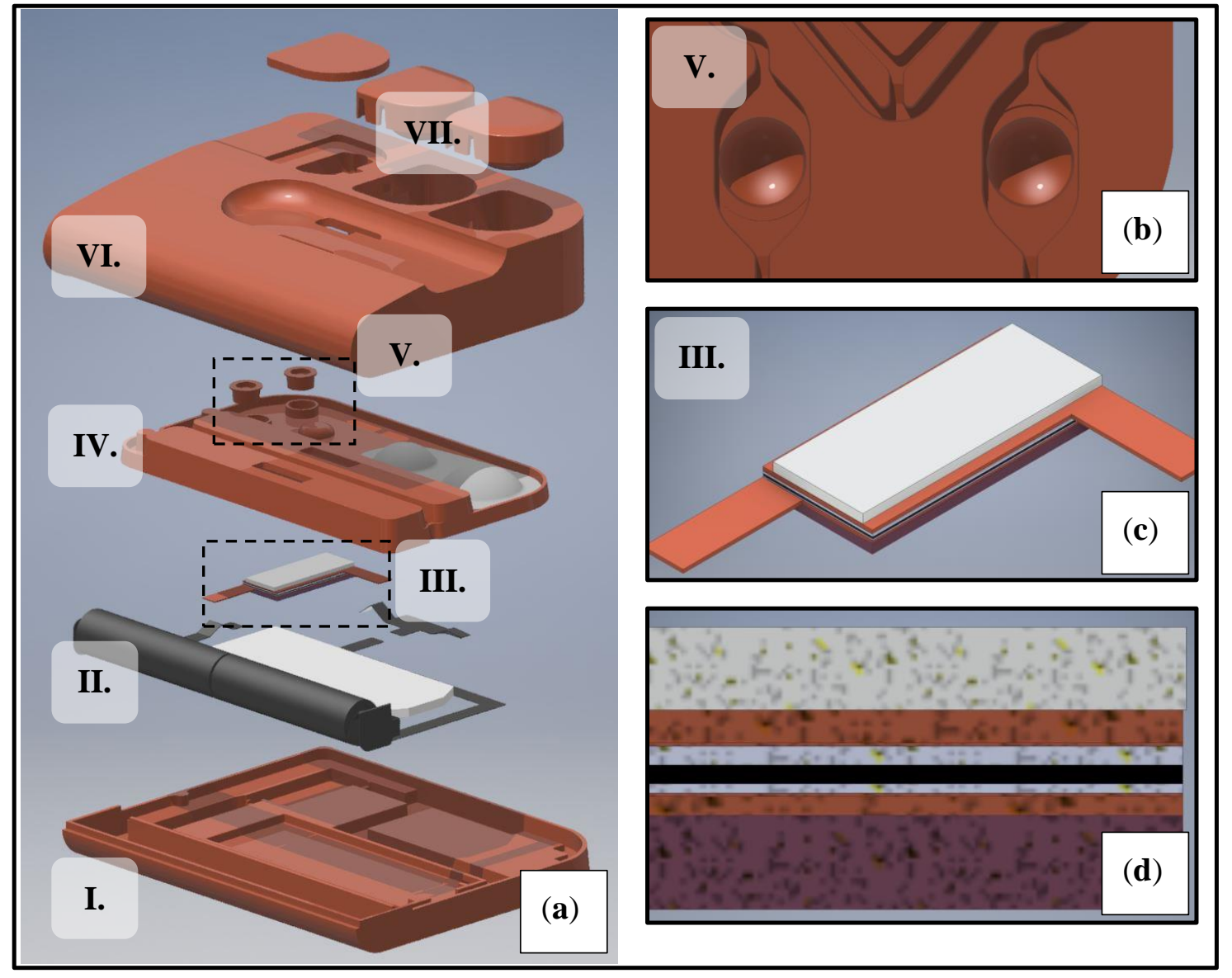

Figure 1. Rendering of experimental setup showing prototype components (a). The setup consisted of the following components: An enclosure (I., VI.) with user interface features (VII.), a microfluidic chip (IV.) with reactor chambers holding a total of $0.1 \mathrm{~mL}$ volume (V.) and the Heatron BM128 self-regulating heater in a sub-assembly (III.) connected to its power supply (II.). The reactor chambers (b), the heater (c) and the layer structure of the heater $(\mathbf{d})$ are shown separately in magnified view. 
Table 2. Summary of material properties used in the model.

\begin{tabular}{ccccc}
\hline Material & Density $\left[\mathbf{k g} / \mathbf{m}^{3}\right]$ & $\begin{array}{c}\text { Thermal } \\
\text { Conductivity } \\
\text { [W/mK] }\end{array}$ & $\begin{array}{c}\text { Specific Heat } \\
\text { Capacity [J/kgK] }\end{array}$ & $\begin{array}{c}\text { Electrical } \\
\text { Conductivity } \\
{[\mathbf{S} / \mathbf{m}]}\end{array}$ \\
\hline PTCR heater resin & 2250 & 1.26 & 1000 & $0.3-0.06$ \\
Aluminum & 2700 & 238 & 900 & $\left(20-65^{\circ} \mathrm{C}\right.$ range) \\
Copper & 8960 & 400 & 385 & $57.7 \times 10^{6}$ \\
Polycarbonate & 1200 & 0.14 & 1250 & Not relevant \\
Air & 1225 & 0.024 & 1000 & Not relevant \\
Water & 1000 & 0.6 & 4184 & Not relevant \\
Polyurethane & 1250 & 0.3 & 1760 & Not relevant \\
Acrylic foam & 850 & 0.18 & 1470 & Not relevant \\
Paper (LF strip) & 1500 & 0.05 & 1340 & Not relevant \\
Steel & 7850 & 44.5 & 475 & $4.03 \times 10^{6}$ \\
\hline
\end{tabular}

\subsection{Thermal Modelling}

The thermal model detailed in this work is usable for both steady-state and transient thermal analyses, given an experimentally characterized resistive heating element and a 3D device geometry with well-defined structural materials and boundary conditions. The core of the model is the heater, which generates a volumetric heat flux $Q$ via Joule heating:

$$
\begin{gathered}
\mathrm{Q}=\mathrm{J} \cdot \mathrm{E} \\
\nabla \mathrm{J}=\mathrm{Q}_{\mathrm{j}} \\
\mathrm{J}=\left(\sigma+\epsilon_{0} \epsilon_{\mathrm{r}} \frac{\partial}{\partial \mathrm{t}}\right) \mathrm{E} \\
\mathrm{E}=-\nabla \mathrm{V}
\end{gathered}
$$

where J, E, $\mathrm{Q}_{\mathrm{j}}$ and $\mathrm{V}$ are the current density, electric field, current sources (sinks) and potential drop in the heating element, respectively. $\sigma$ characterizes the temperature-dependent conductivity (reciprocal of resistivity) of the PTCR polymer resin in the heating element (calculated from the resistance model in Section 3.1). The generated heat is propagated in the device via the heat transfer equation, assuming zero flow (during amplification the reaction liquid is stationary). Structural materials in the simulated geometry are characterized electrically (conductivity, relative permittivity) and thermally (density, heat conductivity, specific heat capacity), as detailed in Table 2. Boundary conditions and initial values applied to the model are listed in Table 3. The experimental device was tested in a climate chamber, which provided a constant ambient temperature. Therefore, ambient temperature in the model was also considered constant.

Table 3. Summary of boundary conditions and initial parameter values used in the model.

\begin{tabular}{ccc}
\hline Boundary Condition & Boundary & Initial Value (If Applicable) \\
\hline Ambient temperature & External boundaries & As defined in text \\
Ambient pressure (absolute) & External boundaries & 1 atm \\
Electric potential & Heater (top) & $3 \mathrm{~V}$ \\
Ground & Heater (bottom) & $0 \mathrm{~V}$ \\
Convective heat loss & External boundaries & Not applicable \\
Electrical insulation & Heater boundaries except contacts & Not applicable \\
Radiative heat loss & External boundaries & Not applicable \\
Joule heating (boundary) & Heater boundaries & Not applicable \\
\hline
\end{tabular}

The model was implemented in COMSOL ${ }^{\circledR}$ Multiphysics version 5.3 using the Heat Transfer and Electric Currents interfaces coupled through the Joule Heating interface. The model was solved via the built-in stationary and time-dependent solvers of COMSOL on a PC with a Core i7-7700 CPU with 
32 GB RAM. Three-dimensional model geometry (Figure 1) was imported from Autodesk Inventor. Convective, conductive and radiative heat losses were taken into account in the model. All physical domains of the experimental device were taken into account in the simulation, but the geometry of the device was defeatured to decrease mesh complexity. The temperature sensor in the physical prototype was modelled by a Domain Point Probe. COMSOL generated a tetrahedral mesh of 3,663,651 elements with an average element quality (based on the well-known radius ratio method [39]) of 0.65 and an element size of $0.05 \mathrm{~mm}^{3}$.

\subsection{Experimental Setup for Thermal Characterization}

The experimental setup was a thermal mock-up $(8 \mathrm{~cm} \times 10 \mathrm{~cm} \times 2 \mathrm{~cm})$ for the instrument-free isothermal NAAT LoC platform currently under development in our labs (Figure 1a). The prototype included a microfluidic chip $(5.5 \mathrm{~cm} \times 9 \mathrm{~cm} \times 0.75 \mathrm{~cm})$ with 2 microreactors with $0.05 \mathrm{~mL}$ volume each (Figure 1b), and the adjacent microchannels. The fluidic chip had 4 fluidic connections (2 inlets, 2 outlets) and was filled with distilled water for the experiments through its inlets, after which the fluidic I/O features were taped over. The reaction chambers were sealed by plastic caps attached with thermoplastic adhesive. One cap had the K-type thermocouple attached to it via a hole drilled through the plastic cap and sealed with adhesive. The chip was interfaced with the heater sub-assembly mentioned in Section 2.1 (Figure 1c). The device prototype included 2xAAA alkaline batteries connected with the heater via steel clips. In the end-user device a switch would be part of the circuit, but in the prototype the switch gap was bridged by a wire. A 3 V LED backlight module (23 mm $\times 60 \mathrm{~mm}$, from Dayear Electronic Co., Ltd., Hong Kong, China) was also part of the circuit, connected in parallel with the heater. In the end-user device, this LED would illuminate the lateral flow strips situated above it in the microfluidic chip, in order to increase contrast during readout. The device enclosure consisted of a bottom and a top part, held together by a snap-fit design. In the final device, the top enclosure would include user I/O interfaces (e.g., buttons to actuate liquids) to the chip. In the prototype, interfacial features were simplified models.

Plastic device components were 3D printed by an SLA 3D printing system (Envisiontec Perfactory $\mathrm{XL}$, Envisiontec $\mathrm{GmbH}$, Gladbeck, Germany), and the channels of the microfluidic chip were sealed with Greiner MTP sealers (Greiner Holding AG, Kremsmunster, Austria). Metal clips were milled by a DATRON M7 (Datron AG, Mühltal, Germany) NC milling machine and then formed manually where needed.

\section{Results and Discussion}

\subsection{Characterization of Heating Element}

To get an accurate model for our thermal system, the temperature-dependent resistance profile of the self-regulating heating element had to be recorded. To this end, we set up the heater with electrical contacts in between sheets of low-density polyurethane foam (P/N 798-9310, RS Components, Corby, UK) and attached a K-type thermocouple sensor on top. The heater was powered from an Agilent E3631A triple-channel DC power supply (Agilent Technologies Inc., Santa Clara, CA, USA). Temperature was recorded with a TENMA 72-7715 digital multimeter (Tenma Test Equipment, Springboro, $\mathrm{OH}, \mathrm{USA})$. Resistance was calculated from the input current values recorded by the power supply at a stable $3 \mathrm{~V}$ input with 2 A current limit. Numerical data in this work was recorded with double-digit precision, except for temperature data where the measurement instrument was limited to single-digit precision. Figure 2 shows the relation between heater surface temperature and resistance. 


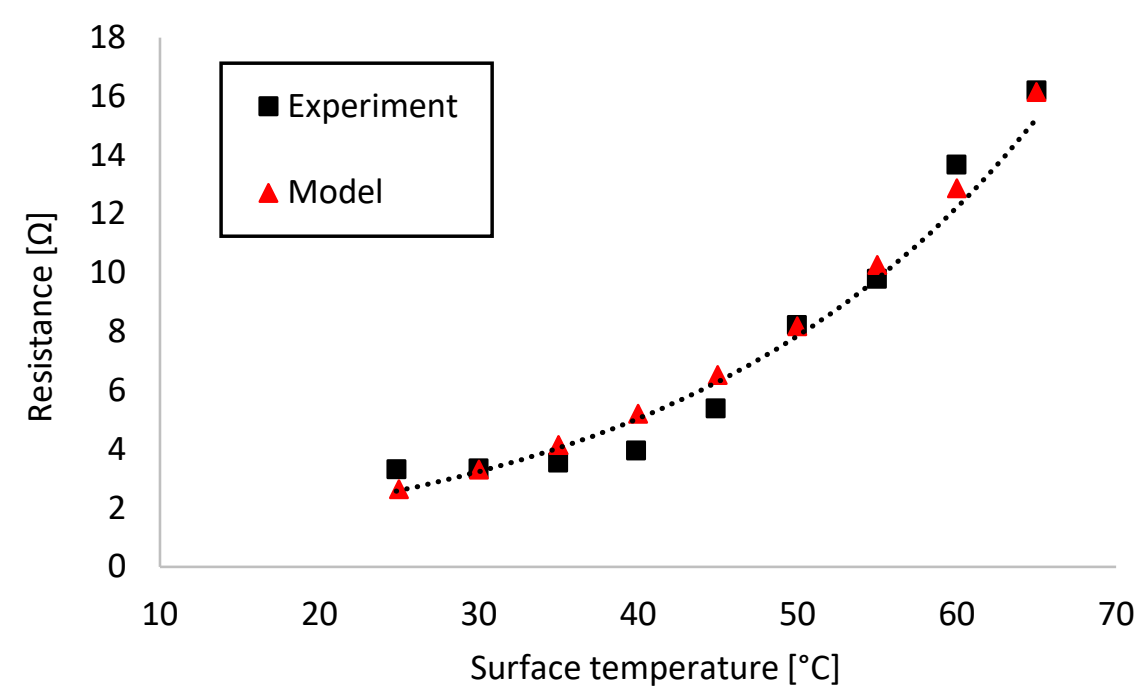

Figure 2. Temperature-dependent resistance profile of BM128 PTC polymer heating elements. The self-regulating heater was characterized by measuring its surface temperature and current input while receiving a steady $3 V_{D C}$ input. The model was found by exponential curve fitting.

Exponential regression analysis was performed on the data in Microsoft Excel and yielded the following expression:

$$
\mathrm{R}=0.85 \cdot \mathrm{e}^{0.0453 \cdot \mathrm{T}}
$$

where $\mathrm{T}\left[{ }^{\circ} \mathrm{C}\right]$ was the surface temperature of the heating element and $R[\Omega]$ was its resistance. The model showed a good fit with the experimental data $\left(R^{2}=0.94\right)$. Resistivity values required by the simulation were calculated from Equation (2) using the well-known formula for resistors with uniform cross-section.

Temperature recording experiments were conducted on a 3D printed physical prototype placed in a Vötsch VT 7004 (Vötsch Industrietechnik GmbH, Bailingen, Germany) climate chamber to ensure a constant ambient temperature. Temperature inside the device prototype was recorded with a TENMA 72-7715 digital multimeter (Tenma Test Equipment, Springboro, OH, USA). The device and the multimeter were placed in the climate chamber and the ambient temperature set, after which the system was allowed $30 \mathrm{~min}$ to reach steady state. Then the chamber was briefly opened to insert the batteries and start the test. Reaction temperature was recorded for $30 \mathrm{~min}$, after which the prototype was disassembled and allowed to reach room temperature before the next test cycle. The experiment was performed in the $15-30{ }^{\circ} \mathrm{C}$ ambient temperature range with $5{ }^{\circ} \mathrm{C}$ steps, each time with a fresh set of batteries to ensure repeatability.

Table 4 summarizes heat-up times to the target range as well as time constants and the estimated power consumption of the heating element, whereas Table 5 summarizes steady-state reaction temperatures in the device. Power consumption $\mathrm{P}[\mathrm{W}]$ was calculated from the well-known $\mathrm{P}=\mathrm{U}^{2} / \mathrm{R}$ expression, where $\mathrm{U}=3 \mathrm{~V}$ and $\mathrm{R}$ was calculated from Equation (2). The time constant for the thermal system in the device was $\sim 27 \mathrm{~min}$. Test results indicated that the reaction liquid in the device reached the correct steady-state reaction temperature range when ambient temperatures were between $20-25^{\circ} \mathrm{C}$, which is typically considered room temperature. Below this range it would take too long to reach target range, whereas above there would be a risk of overheating the reaction. Heat-up times were within the required $10 \mathrm{~min}$ only at $25-30^{\circ} \mathrm{C}$. The ideal ambient temperature was measured to be $25^{\circ} \mathrm{C}$, at which the steady-state temperature was $59.9 \pm 0.05^{\circ} \mathrm{C}$, and the $57^{\circ} \mathrm{C}$ target was reached in $8.5 \mathrm{~min}$, both compliant with assay specifications. 
Table 4. Summary of heat-up times and time constants for the recorded thermal transients, as well as power consumption of the heating element.

\begin{tabular}{cccc}
\hline $\begin{array}{c}\text { Ambient } \\
\text { Temperature }\left[{ }^{\circ} \mathbf{C}\right]\end{array}$ & $\begin{array}{c}\text { Heat-Up Time to } \\
\mathbf{5 7}{ }^{\circ} \mathbf{C}[\mathbf{m i n}]\end{array}$ & Time Constant [min] & Power Consumption [W] \\
\hline 15 & 20 & 27.5 & 0.94 \\
20 & 10.5 & 27 & 0.86 \\
25 & 8.5 & 27.5 & 0.84 \\
30 & 5.5 & 26 & 0.76 \\
\hline
\end{tabular}

Table 5. Summary of experimental and simulated steady-state reaction temperatures and reaction volume in range values in the $15-30{ }^{\circ} \mathrm{C}$ ambient temperature range with $5{ }^{\circ} \mathrm{C}$ steps.

\begin{tabular}{cccc}
\hline $\begin{array}{c}\text { Ambient } \\
\text { Temperature }\left[{ }^{\circ} \mathbf{C}\right]\end{array}$ & $\begin{array}{c}\text { Experimental } \\
\text { Steady-State }\left[{ }^{\circ} \mathbf{C}\right]\end{array}$ & $\begin{array}{c}\text { Simulated Steady-State } \\
{\left[{ }^{\circ} \mathbf{C}\right]}\end{array}$ & $\begin{array}{c}\text { Reaction Volume in } \\
\text { Range }[\%]\end{array}$ \\
\hline 15 & 57.5 & 57.3 & 24 \\
20 & 59.5 & 59.2 & 92 \\
25 & 59.9 & 60.3 & 100 \\
30 & 62.3 & 63.1 & 56 \\
\hline
\end{tabular}

\subsection{Steady-State Thermal Analysis}

To assess heating performance in the designated operating ambient temperature range, steady-state thermal analysis was conducted. Initially, the simulated thermal model was verified by comparing to the experimental data. Next, steady-state performance was estimated by calculating the ratio of the reaction volume in range versus the total volume. Steady-state temperature was defined as the mean of the last $5 \mathrm{~min}$ of the recorded data points, where variation was negligible $\left(<0.1{ }^{\circ} \mathrm{C}\right.$ standard deviation). Steady-state temperatures were calculated from the experimental data shown in Figure 3.

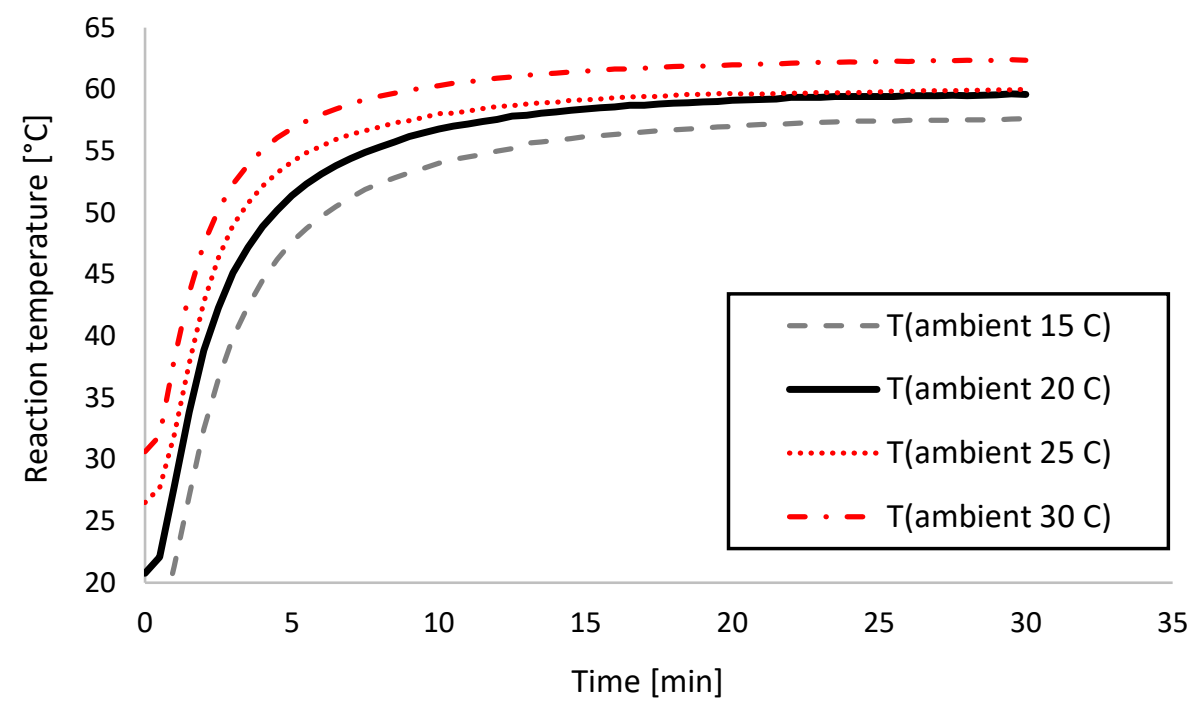

Figure 3. Thermal transient recordings for the experimental prototype. Each recording was conducted for $30 \mathrm{~min}$ in a pre-heated climate chamber.

The model was set up as described in Section 2.2 and solved using the Stationary Solver of COMSOL ${ }^{\circledR}$ Multiphysics. Running a parametric sweep with all four ambient temperature points, the solution time was $48.5 \mathrm{~min}$. The mean absolute error (MAE) between experimental and simulated data points was $0.4^{\circ} \mathrm{C}$. Generally, models tend to overestimate heat output in simulated thermal systems due to the fact that simulated thermal interfaces are ideal and losses are typically 
underestimated. In this model, this tendency was observed beyond $20^{\circ} \mathrm{C}$ as the model increasingly overestimated real data. The effect was compounded by the complexity of the heater assembly (air pockets potentially stuck between self-adhesive layers).

LAMP is a very robust amplification protocol, it is well suited for use in an LoC setting, and provides excellent yield as long as it is run at the correct reaction temperature [7]. In our previous paper [34], we proved that when at least $\sim 85 \%$ of the reaction liquid was in range in the chip, the reaction would complete successfully. Given that the microreactor geometry as well as the heater surface area and alignment relative to the reactors were unchanged in the chip used in this paper, we worked with the same assumption. Therefore, we estimated the percentage of the reaction liquid in range using the methodology demonstrated in our previous work [33], evaluating the logical condition $\left(\mathrm{T}>56.99\left[{ }^{\circ} \mathrm{C}\right] \cap \mathrm{T}<62.01\left[{ }^{\circ} \mathrm{C}\right]\right) \in\{0 ; 1\}$ for each finite element within the microreactor cavity of our COMSOL model. This can be expressed with the following formula:

$$
\eta=100 \cdot \frac{1}{\mathrm{n}} \sum_{\mathrm{i}=1}^{\mathrm{n}}\left(\left(\mathrm{T}_{\mathrm{i}}>56.99\left[{ }^{\circ} \mathrm{C}\right] \cap \mathrm{T}_{\mathrm{i}}<62.01\left[{ }^{\circ} \mathrm{C}\right]\right) \in\{0 ; 1\}\right)
$$

where $T_{i}$ denotes temperature values for each finite element, $n$ the total element number and $\eta \in[0 ; 100]$. Table 5 summarizes temperature data and estimated reaction volumes in range at the ambient temperatures specified in the previous section. Figure 4 shows a graphical comparison between experimental and simulated reaction temperature data, as well as reaction volume in range relative to ambient temperature.

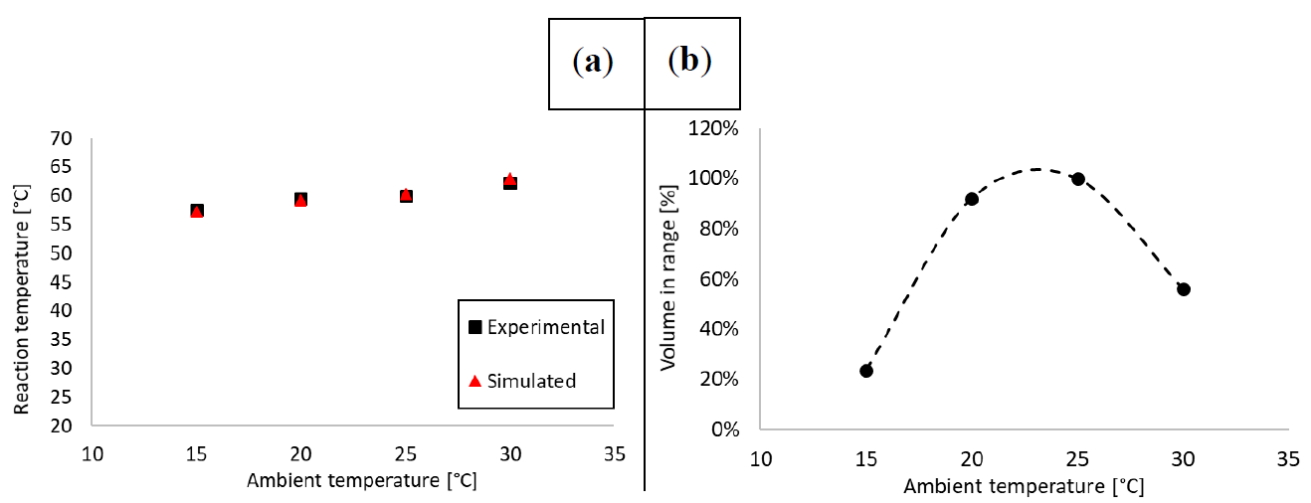

Figure 4. Experimental and simulated steady-state temperatures (a) as well as estimated reaction volume in range $(\mathbf{b})$. Data points were recorded in the $15-30{ }^{\circ} \mathrm{C}$ temperature range with $5{ }^{\circ} \mathrm{C}$ steps, corresponding to the full ambient range expected at the end-user side (homes and offices). Based on our assessment, the device would perform best within $20-25^{\circ} \mathrm{C}$, which is commonly referred to as room temperature. At $25^{\circ} \mathrm{C}, 100 \%$ of the reaction liquid was in range in steady-state. Below $20^{\circ} \mathrm{C}$, the test would require longer than $30 \mathrm{~min}$ to finish, whereas above $30^{\circ} \mathrm{C}$, polymerase activity would be insufficient, likely leading to false negatives.

To summarize, steady-state thermal analysis was conducted on our concept device at $15-30{ }^{\circ} \mathrm{C}$ ambient temperatures with $5{ }^{\circ} \mathrm{C}$ steps. The device was modelled with a simulation to reveal the volume of the reaction liquid in range. In the $20-25^{\circ} \mathrm{C}$ ambient temperature range, typically considered as room temperature, the device met the target temperature criterion in our experiments as well as had an estimated $90-100 \%$ of the reaction liquid in the range based on our models. Heating efficiency peaked at $25{ }^{\circ} \mathrm{C}$ ambient temperature. Below $20^{\circ} \mathrm{C}$ the reaction would need considerably more time to finish than $30 \mathrm{~min}$, and above $30^{\circ} \mathrm{C}$ the activity of the Bsm polymerase would diminish significantly until it became completely inactivated. Therefore, our proposed device design was proven valid for use in the $20-25^{\circ} \mathrm{C}$ ambient temperature range (common in homes and offices) with respect to steady-state temperatures. 


\subsection{Transient Thermal Analysis}

As described in the previous section, the steady-state temperature target stated in Section 2.1 was met in the $20-25^{\circ} \mathrm{C}$ ambient temperature range. The other assay criterion to meet was the rise time to the target range (10 min maximum) and the total time in range (20 min minimum). All these criteria were only possible to meet at $25^{\circ} \mathrm{C}$ ambient temperature, which we analyzed further with transient thermal analysis. First, we took the experimentally recorded thermal transients shown in Figure 3 and compared them to the output of the simulation to verify their accuracy. Then we calculated Equation (3) for all simulated time points to determine the percentage of the reaction volume in range.

The model was once more set up as described in Section 2.2 and solved using the Time-Dependent Solver of COMSOL ${ }^{\circledR}$ Multiphysics. Solution time was $2 \mathrm{~h} 39 \mathrm{~min}$ for a simulated transient of $30 \mathrm{~min}$. The MAE between experimental and simulated data points was $1.2^{\circ} \mathrm{C}$ at $25^{\circ} \mathrm{C}$ ambient temperature, and the model estimated both the heat-up time and the time constant accurately. Figure 5 shows the results of the transient thermal analysis.

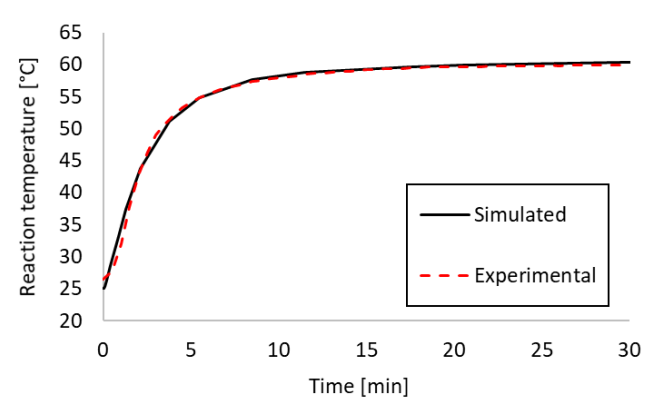

(a)

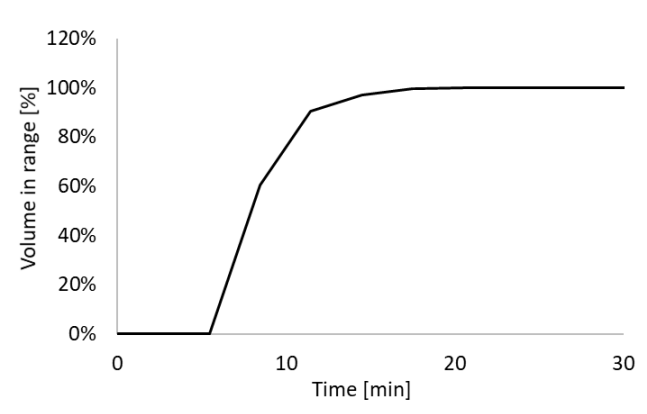

(b)

Figure 5. Experimental and simulated thermal transients for the reaction temperature in the device (a) as well as estimated reaction volume in range in time (b). Data points were recorded and simulated at $25^{\circ} \mathrm{C}$ ambient temperature.

As stated previously $\sim 85 \%$ of the reaction volume (in the reaction chambers) had to be in the target temperature range $57-62{ }^{\circ} \mathrm{C}$ for the reaction to be successful. Analyzing the percentage of the reaction volume in range using Equation (3), we can conclude that within $10 \mathrm{~min}$ the required $\sim 85 \%$ of the volume was in range. With the current device concept and assay requirements, the device would work most reliably at $25^{\circ} \mathrm{C}$ ambient temperature. While the temperature sensor measured $57^{\circ} \mathrm{C}$ already at $8.5 \mathrm{~min}$, it took $\sim 10 \mathrm{~min}$ for the majority of the reaction volume to reach the target range. Considering this $1.5 \mathrm{~min}$ difference, the operating ambient temperature range of the device could easily be extended to include $20^{\circ} \mathrm{C}$ with one of two options: (1) Extending the total assay time to at least $32 \mathrm{~min}$, (2) adding additional insulation. Option (2) is not easily practicable for a well-established system given that any added insulation takes up additional space, changes the thermal system and mandates a design overhaul. Option (1) is far easier to implement and is an acceptable trade-off to ensure that no false negatives occur on the end-user side.

\section{Conclusions}

In this work we demonstrated a thermal analysis methodology for the evaluation of LoC NAAT devices. The proposed process was demonstrated on a simplified thermal model for an instrument-free single-use LoC NAAT platform with integrated temperature control via a self-regulating polymer resin heater. The LoC component was designed to house a LAMP reaction for chlamydia trachomatis $(\mathrm{CT})$, established in our previous works. This assay required $57-62{ }^{\circ} \mathrm{C}$ reaction temperature and at least $20 \mathrm{~min}$ incubation time. Therefore, experimental and simulated steady-state thermal analysis was performed to establish compliance with the temperature target at ambient temperatures between $15-30{ }^{\circ} \mathrm{C}$ with $5{ }^{\circ} \mathrm{C}$ steps. Our proposed finite element model estimated steady-state temperatures 
with $0.4{ }^{\circ} \mathrm{C}$ error and was used to estimate reaction volumes in range in steady-state to verify assay compliance. In our previous work we demonstrated that at least $\sim 85 \%$ of the reaction liquid had to be in range for a successful reaction. This condition was met in the $20-25{ }^{\circ} \mathrm{C}$ ambient temperature range. Thermal transients were recorded for the experimental thermal model and determined that the test would perform best at $25^{\circ} \mathrm{C}$ ambient temperature. The simulated thermal transient was within $1.2^{\circ} \mathrm{C}$ of the experimental record and was used again to estimate the reaction volume in range over time. It was determined that $\sim 85 \%$ of the reaction volume was in range after $10 \mathrm{~min}$ and thus the $20 \mathrm{~min}$ incubation time criterion was possible to meet with $30 \mathrm{~min}$ assay time. However, to extend the operating ambient temperature range of the device to the $20-25^{\circ} \mathrm{C}$ room temperature range, the total assay time would need to be extended to $32 \mathrm{~min}$.

Summarily, we demonstrated a comprehensive thermal analysis methodology to verify assay compliance in LoC NAAT devices and performed the analysis to demonstrate our proposed LoC NAAT platform capable of executing our CT-LAMP assay at $20-25{ }^{\circ} \mathrm{C}$ ambient temperature under $32 \mathrm{~min}$. The demonstrated heating solution offers a unique combination of power-efficiency $(\sim 1 \mathrm{~W}$ max., on 2xAAA alkaline batteries), small size $(1 \mathrm{~cm} \times 2 \mathrm{~cm} \times 0.5 \mathrm{~cm})$, low cost $(\sim 20-50$ EUR end-user device price) and good disposability (no toxic structural materials). Furthermore, it is realized by using only passive electronic components in a minimalistic and fully self-contained design that enables disposal as a unit after each use. This set of features address several of the barriers to commercializing LoC NAAT systems, and it is our hope that this contribution will bring affordable homecare DNA analysis along with its benefits to preventive medicine one step closer.

\section{Patents}

Selfdiagnostics Deutschland GmbH has a pending patent application (PA201770310) that details the integration of polymer resin heating elements into Lab-on-a-Chip devices.

Author Contributions: T.P. and I.T. conceived and designed the experiments; T.P. performed the experiments; T.P., I.T. and T.R. analyzed the data; T.P. built the finite element models for thermal analysis; T.R. and I.T. contributed materials and analysis tools; T.P. wrote the paper; I.T. and T.R. provided support and supervision.

Acknowledgments: The authors wish to express their gratitude to the Sächsische AufbauBank for their support under project SAB\#100204668, to the European Commission for support under the Horizon 2020 SME Instrument Phase II funding programme (Project ID: 666852, url: http://cordis.europa.eu/project/ rcn/197912_en.html), the Estonian Research Council for support under Institutional Research Project IUT19-11, the European Commission for support under Horizon 2020 ERA-chair Grant 'Cognitive Electronics COEL'-H2020-WIDESPREAD-2014-2 (Agreement number: 668995; project TTU code VFP15051), as well as to TAR16013 Center of Excellence 'EXCITE IT'.

Conflicts of Interest: The authors declare no conflict of interest. The funding sponsors had no role in the design of the study; in the collection, analyses, or interpretation of data; in the writing of the manuscript, and in the decision to publish the results.

\section{References}

1. Dye, C. After 2015: Infectious diseases in a new era of health and development. Philos. Trans. R. Soc. B Biol. Sci. 2014, 369, 20130426. [CrossRef] [PubMed]

2. Satterwhite, C.L.; Torrone, E.; Meites, E.; Dunne, E.F.; Mahajan, R.; Ocfemia, M.C.B.; Su, J.; Xu, F.; Weinstock, H. Sexually Transmitted Infections among US Women and Men: Prevalence and Incidence Estimates, 2008. Sex. Trans. Dis. 2013, 40, 187-193. [CrossRef] [PubMed]

3. Drain, P.K.; Hyle, E.P.; Noubary, F.; Freedberg, K.A.; Wilson, D.; Bishai, W.R.; Rodriguez, W.; Bassett, I.V. Diagnostic point-of-care tests in resource-limited settings. Lancet Infect. Dis. 2014, 14, 239-249. [CrossRef]

4. Srinivasan, V.; Pamula, V.K.; Fair, R.B. An integrated digital microfluidic lab-on-a-chip for clinical diagnostics on human physiological fluids. Lab Chip 2004, 4, 310. [CrossRef] [PubMed]

5. Mark, D.; Haeberle, S.; Roth, G.; Von Stetten, F.; Zengerle, R. Microfluidic Lab-on-a-Chip Platforms: Requirements, Characteristics and Applications. In Microfluidics Based Microsystems; Kakaç, S., Kosoy, B., Li, D., Pramuanjaroenkij, A., Eds.; Springer Netherlands: Dordrecht, The Netherlands, 2010; pp. 305-376. ISBN 978-90-481-9028-7. 
6. Pais, A.; Banerjee, A.; Klotzkin, D.; Papautsky, I. High-sensitivity, disposable lab-on-a-chip with thin-film organic electronics for fluorescence detection. Lab Chip 2008, 8, 794. [CrossRef] [PubMed]

7. Craw, P.; Balachandran, W. Isothermal nucleic acid amplification technologies for point-of-care diagnostics: A critical review. Lab Chip 2012, 12, 2469. [CrossRef] [PubMed]

8. Mori, Y.; Notomi, T. Loop-mediated isothermal amplification (LAMP): A rapid, accurate, and cost-effective diagnostic method for infectious diseases. J. Infect. Chemother. 2009, 15, 62-69. [CrossRef] [PubMed]

9. Asiello, P.J.; Baeumner, A.J. Miniaturized isothermal nucleic acid amplification, a review. Lab Chip 2011, 11, 1420. [CrossRef] [PubMed]

10. Oblath, E.A.; Henley, W.H.; Alarie, J.P.; Ramsey, J.M. A microfluidic chip integrating DNA extraction and real-time PCR for the detection of bacteria in saliva. Lab Chip 2013, 13, 1325. [CrossRef] [PubMed]

11. Schumacher, S.; Nestler, J.; Otto, T.; Wegener, M.; Ehrentreich-Förster, E.; Michel, D.; Wunderlich, K.; Palzer, S.; Sohn, K.; Weber, A.; et al. Highly-integrated lab-on-chip system for point-of-care multiparameter analysis. Lab Chip 2012, 12, 464-473. [CrossRef] [PubMed]

12. Rival, A.; Jary, D.; Delattre, C.; Fouillet, Y.; Castellan, G.; Bellemin-Comte, A.; Gidrol, X. An EWOD-based microfluidic chip for single-cell isolation, mRNA purification and subsequent multiplex qPCR. Lab Chip 2014, 14, 3739-3749. [CrossRef] [PubMed]

13. Sun, Y.; Quyen, T.L.; Hung, T.Q.; Chin, W.H.; Wolff, A.; Bang, D.D. A lab-on-a-chip system with integrated sample preparation and loop-mediated isothermal amplification for rapid and quantitative detection of Salmonella spp. in food samples. Lab Chip 2015, 15, 1898-1904. [CrossRef] [PubMed]

14. Nie, S.; Roth, R.B.; Stiles, J.; Mikhlina, A.; Lu, X.; Tang, Y.-W.; Babady, N.E. Evaluation of Alere I Influenza A\&B for Rapid Detection of Influenza Viruses A and B. J. Clin. Microbiol. 2014, 52, 3339-3344. [CrossRef] [PubMed]

15. Kaprou, G.; Papadakis, G.; Kokkoris, G.; Papadopoulos, V.; Kefala, I.; Papageorgiou, D.; Gizeli, E.; Tserepi, A. Miniaturized devices towards an integrated lab-on-a-chip platform for DNA diagnostics. In Bio-MEMS and Medical Microdevices II; van den Driesche, S., Ed.; International Society for Optics and Photonics: Bellingham, DC, USA, 2015; p. 95180G.

16. Gurrala, R.; Lang, Z.; Shepherd, L.; Davidson, D.; Harrison, E.; McClure, M.; Kaye, S.; Toumazou, C.; Cooke, G.S. Novel pH sensing semiconductor for point-of-care detection of HIV-1 viremia. Sci. Rep. 2016, 6, 36000. [CrossRef] [PubMed]

17. Lafleur, L.K.; Bishop, J.D.; Heiniger, E.K.; Gallagher, R.P.; Wheeler, M.D.; Kauffman, P.; Zhang, X.; Kline, E.C.; Buser, J.R.; Kumar, S.; et al. A rapid, instrument-free, sample-to-result nucleic acid amplification test. Lab Chip 2016. [CrossRef] [PubMed]

18. Wang, C.-H.; Lien, K.-Y.; Wang, T.-Y.; Chen, T.-Y.; Lee, G.-B. An integrated microfluidic loop-mediated-isothermal-amplification system for rapid sample pre-treatment and detection of viruses. Biosens. Bioelectron. 2011, 26, 2045-2052. [CrossRef] [PubMed]

19. Moschou, D.; Vourdas, N.; Kokkoris, G.; Papadakis, G.; Parthenios, J.; Chatzandroulis, S.; Tserepi, A. All-plastic, low-power, disposable, continuous-flow PCR chip with integrated microheaters for rapid DNA amplification. Sens. Actuators B Chem. 2014, 199, 470-478. [CrossRef]

20. Maltezos, G.; Johnston, M.; Scherer, A. Thermal management in microfluidics using micro-Peltier junctions. Appl. Phys. Lett. 2005, 87, 154105. [CrossRef]

21. Maltezos, G.; Gomez, A.; Zhong, J.; Gomez, F.A.; Scherer, A. Microfluidic polymerase chain reaction. Appl. Phys. Lett. 2008, 93, 243901. [CrossRef]

22. Van Bokestal, A.M.A.; Belhomme, C.J.G.; North American Philips Lighting Corp. Self-Regulating Heating Element. U.S. Patent 4104509A, 23 September 1975.

23. Khazai, B.; Nichols, G.M. Nichols Self-Regulating Polymer Composite Heater. U.S. Patent 5,902,518, 11 May 1999.

24. Wyzkiewicz, I.; Grabowska, I.; Chudy, M.; Brzozka, Z.; Jakubowska, M.; Wisniewski, T.; Dybko, A. Self-regulating heater for microfluidic reactors. Sens. Actuators B Chem. 2006, 114, 893-896. [CrossRef]

25. Buser, J.R.; Diesburg, S.; Singleton, J.; Guelig, D.; Bishop, J.D.; Zentner, C.; Burton, R.; LaBarre, P.; Yager, P.; Weigl, B.H. Precision chemical heating for diagnostic devices. Lab Chip 2015, 15, 4423-4432. [CrossRef] [PubMed]

26. Weigl, B.; Domingo, G.; LaBarre, P.; Gerlach, J. Towards non- and minimally instrumented, microfluidics-based diagnostic devices. Lab Chip 2008, 8, 1999. [CrossRef] [PubMed] 
27. Sema, M.; Alemu, A.; Bayih, A.; Getie, S.; Getnet, G.; Guelig, D.; Burton, R.; LaBarre, P.; Pillai, D.R. Evaluation of non-instrumented nucleic acid amplification by loop-mediated isothermal amplification (NINA-LAMP) for the diagnosis of malaria in Northwest Ethiopia. Malar. J. 2015, 14, 44. [CrossRef] [PubMed]

28. Bar-Cohen, A.; Wang, P. On-Chip Thermal Management and Hot-Spot Remediation. In Nano-Bio-Electronic, Photonic and MEMS Packaging; Wong, C.P., Moon, K.-S., Li, Y., Eds.; Springer: Boston, MA, USA, 2010; pp. 349-429. ISBN 978-1-4419-0039-5.

29. Streit, P.; Nestler, J.; Shaporin, A.; Graunitz, J.; Otto, T. Design methodology and results evaluation of a heating functionality in modular lab-on-chip systems. J. Micromech. Microeng. 2018, 28, 064001. [CrossRef]

30. Pardy, T.; Rang, T.; Tulp, I. Finite element modelling of the resistive heating of disposable molecular diagnostics devices. In WIT Transactions on Modelling and Simulation; WIT Press: Opatija, Croatia, 2015; pp. 381-391.

31. Pardy, T.; Rang, T.; Tulp, I. Modelling and experimental characterisation of thermoelectric heating for molecular diagnostics devices. In Proceedings of the 2016 15th Biennial Baltic Electronics Conference (BEC), Tallinn, Estonia, 3-5 October 2016; pp. 27-30.

32. Pardy, T.; Tulp, I.; Rang, T. Finite Element Modelling for the Optimization of Microheating in Disposable Molecular Diagnostics. In WIT Transactions on Engineering Sciences; WIT Press: Ancona, Italy, 2016; Volume 106.

33. Pardy, T.; Rang, T.; Tulp, I. Development of Temperature Control Solutions for Non-Instrumented Nucleic Acid Amplification Tests (NINAAT). Micromachines 2017, 8, 180. [CrossRef]

34. Pardy, T.; Tulp, I.; Kremer, C.; Rang, T.; Stewart, R. Integrated self-regulating resistive heating for isothermal nucleic acid amplification tests (NAAT) in Lab-on-a-Chip (LoC) devices. PLoS ONE 2017, 12, e0189968. [CrossRef] [PubMed]

35. Tulp, I.; Krolov, K.; Lehes, M.; Langel, U. Method and Its Compositions for Detection of Nucleic Acid Target from Biological Samples and Body Fluids. U.S. Patent 14/437,110, 12 November 2012.

36. Jevtuševskaja, J.; Uusna, J.; Andresen, L.; Krõlov, K.; Laanpere, M.; Grellier, T.; Tulp, I.; Langel, Ü. Combination with antimicrobial peptide lyses improves loop-mediated isothermal amplification based method for Chlamydia trachomatis detection directly in urine sample. BMC Infect. Dis. 2016, 16. [CrossRef] [PubMed]

37. Krõlov, K.; Frolova, J.; Tudoran, O.; Suhorutsenko, J.; Lehto, T.; Sibul, H.; Mäger, I.; Laanpere, M.; Tulp, I.; Langel, Ü. Sensitive and Rapid Detection of Chlamydia trachomatis by Recombinase Polymerase Amplification Directly from Urine Samples. J. Mol. Diagn. 2014, 16, 127-135. [CrossRef] [PubMed]

38. Oscorbin, I.P.; Boyarskikh, U.A.; Filipenko, M.L. Large Fragment of DNA Polymerase I from Geobacillus sp. 777: Cloning and Comparison with DNA Polymerases I in Practical Applications. Mol. Biotechnol. 2015, 57, 947-959. [CrossRef] [PubMed]

39. Friess, H.; Haussener, S.; Steinfeld, A.; Petrasch, J. Tetrahedral mesh generation based on space indicator functions: Tetrahedral mesh generation based on space indicator functions. Int. J. Numer. Methods Eng. 2013, 93, 1040-1056. [CrossRef]

(C) 2018 by the authors. Licensee MDPI, Basel, Switzerland. This article is an open access article distributed under the terms and conditions of the Creative Commons Attribution (CC BY) license (http:/ / creativecommons.org/licenses/by/4.0/). 